the members of these families must be warned against intermarriage, but, as dominant types also occur, it is emphasized that the mode of inheritance must be studied in each case.

\title{
LITERATURE
}

Bardram, M. and Braendstrup, PaUl (1947).-Maternal Rubella during pregnancy as cause of congenital cataract and other congenital malformations. Acta. Ophthal., 25, 354 .

BATESON, W. (1909).-Mendelian principles of heredity. Univ. press.

BÜCKLERS, M. (1938).-Erbliche Linsentrübungen. H.Buch der Erbkrankheiten, 5,112 .

Baker, A. R. (1892).-Infantile cataract. J. Amer. Med. Assoc., 19, 278.

DAHLBERG, G. (1929). - Inbreeding in Man. Genetics, 14.

DUNN, L. (1947).- The Effects of Isolates on the Frequency of rare Human Genes. Proc. of the National Academy of Sciences, 33, No. 12.

Franceschetti, A. (1930).--Die Vererbung von Augenleiden. Kurzes Handbuch der Ophthal., 5, 199.

Jess, A. (1930)--Die Linse und ihre Erkrankungen. Kurzes Handbuch der Ophthai., 5, 199.

KJERRUMGARD, E. (1948).--Retinitis pigmentosa, with special reference to otologic, neurologic and endocrinic complications. Acta. Ophhal., 26, 555.

NeTtLESHip, E. (1905).-On heredity in the various forms of cataract. Roy. Lond. Ophthal. Hosp. Rept., 16, 179.

STARBECK (1877). - Beitrage zur Lehre vom Schichstar. Diss. Strassburg.

WaARdenburg, J. P. (1932). - Das menschliche Auge und seine Erbanlagen. Martinius Nijhoff, Haag.

WEINBERG, W. (1912 or 1913).--Uber neuere psychiatrische Vererbungsstatistik. Arch. Rassenbiol., 9 and 10.

\section{THE MOTOR IMPULSE ELICITED BY THE RETINAL STIMULUS AND THE BINOCULAR OPTICAL REFLEXES*}

BY

\section{J. E. WINKELMAN}

AMSTRRDAM

In order to study the problem of strabismus, it is necessary to investigate the disturbances of the normal binocular reflexes which occur in such patients. To do this, however, an exact knowledge of the essential features of these binocular reflexes in normal persons is required.

We started from the fundamental supposition that' stimulation of a certain part of the retina not only produces a sensory effect, but is àlso active in a motor sense. In our opinion stimulation of the retina gives rise to a sensory and a motor impulse. There is evidence that in general these motor impulses may produce the following four physiologic phenomena: 
Objectively :

I. A sidewards movement of equal amplitude and in the same direction of both eyes; a conjugate movement.

II. A movement of the eyes in opposite direction : disjunctive movement; this results in a fusional movement.

Subjectively (when the motor effect on the muscles is inhibited).

III. Localisation of the stimulus in space.

IV. 'The visual sensation of apparent movement.

We have investigated three of the four reactions (II, III and IV). In the course of our experiments it appeared that in haploscopic alternating stimulation of both retinas with a small luminous spot we had an excellent method for analyzing these reactions.

\section{DESCRIPTION OF THE APPARATUS.}

A narrow strip of wood was fixed on a wooden frame, forming part of the circumference of a circle. Two wooden boxes may be shifted along this strip. Each box is provided with a small hole of $3 \mathrm{~mm}$. diameter in the centre. These holes are covered by transparent paper and are illuminated by a $3 \frac{1}{2}$ volt lamp within the boxes. An alternating device was incorporated in the electrical circuit; this makes it possible to illuminate the boxes alternately. The alternating device is driven by a motor (M) with adjustable speed; by lowering or increasing the speed of the motor the frequency of alternation can be controlled. The latter is measured by a revolution-counter (R), which may be placed on the axis of the alternating device (A). The experiments were carried out in complete darkness. The image of the luminous spot intended for the one eye was screened from the other eye by the interposition of screens (S). Fig. 1 shows the test set-up. By proper adustment of the screens we can stimulate "binasally" (each eye sees homonymous objects) or "bitemporally" (each eye sees heteronymous objects). Both methods of stimulation are shown in Fig. 2. The interval between stimuli was made equal to zero as near as possibile. When, under these circumstances, we apply alternate haploscopic stimulation to the eyes with a low frequency of alternation $(e . g$., each retina receives 20 stimuli in 30 seconds), maximal apparent movement results. When the frequency of stimulation was raised we noticed the following phenomena :

The amplitude of the apparent movement was reduced, whereas the movement retained its optimal character; the subject still had the impression of one object moving over a certain distance. The distance across which the movement was seen, however, lessened.

$A$ further increase of the frequency reduced the amplitude still more, until one object exhibiting slight movements was seen. Still further increase of frequency caused the movement to disappear completely and only one motionless object was seen. These effects resulted from a fusional movement; the motor impulses roused by the alternating retinal stimulation found a concrete expression in this fusional movement.

Increase of frequency, however, may also be followed by another phenomenon. Instead of apparent movement over a smaller distance, simultaneous perception of two objects at the original distance may result (sim-stadium of Wertheimer). This simultaneous perception of two objects is still accompanied by some apparent movement. "The two objects appear to "jump" towards their place and away from it. ("Aufauch" and " Erlösch-Bewegung," Roelofs and Van der Waals.) A further increase of frequency then results in simultaneous perception of two objects separated in space, without any apparent movement.

Summarizing :

Low frequency-maximal apparent movement of one object.

Increase of frequency-either apparent movement over a smaller distance or simultaneous perception of two objects accompanied by "jump" apparent movement. 


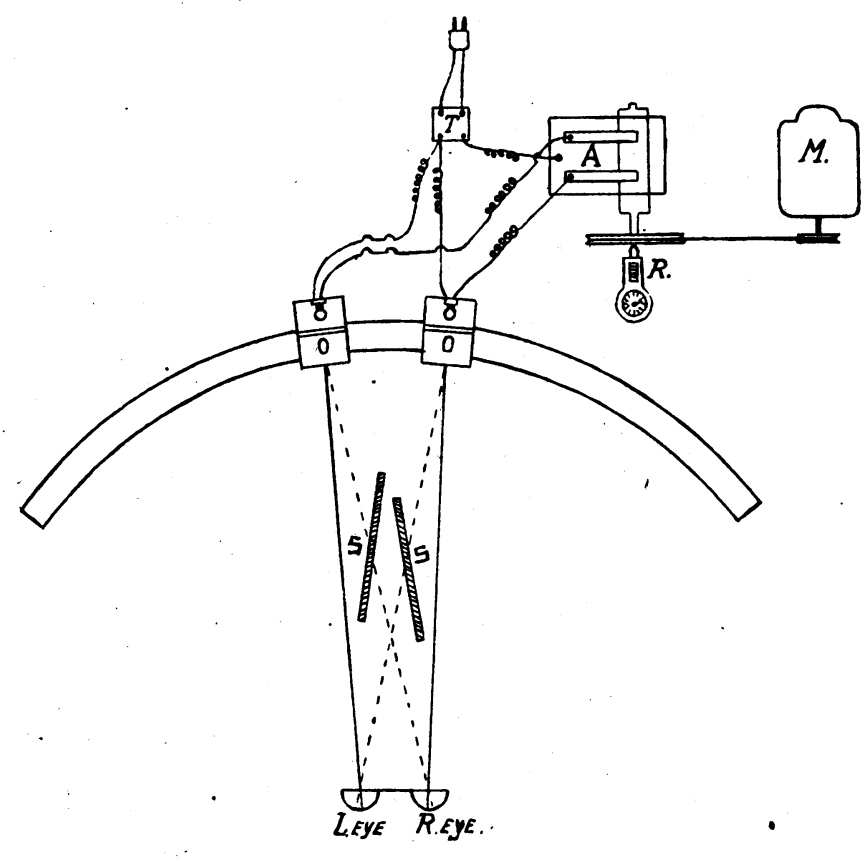

FIG. 1.
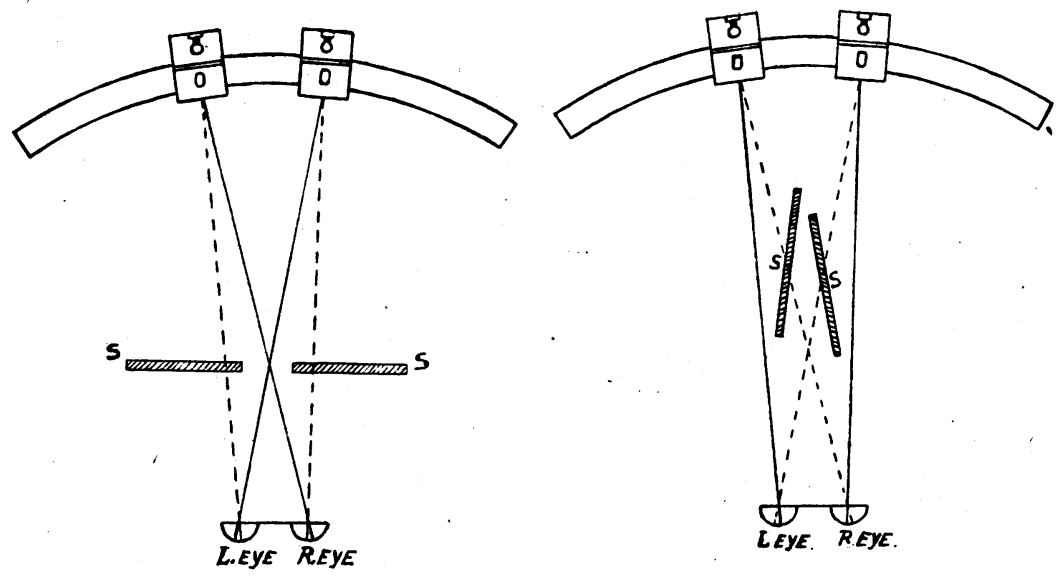

FIG. 2. 
Further increase-either one motionless object or two motionless objects separated in space.

It depends on the outer circumstances which of the two reactions is chosen. The frequency of alternating stimulation is of great significance with regard to the reaction. The maximal apparent movement seen with low frequency is gradually transferred to the standstill of one object with increase of frequency. In our experiments we tried to establish the frequency of the alternating stimuli required for the different phases of the above mentioned process.

The following steps were paid attention to:

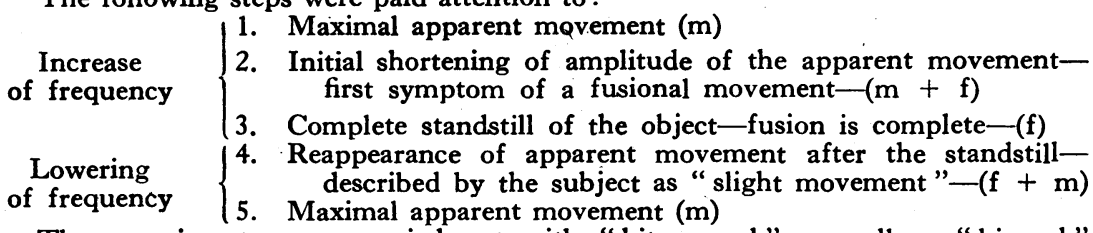

The experiments were carried out with "bitemporal" as well as "binasal" stimulation (see Fig. 2). The distance between the subject and stimulating objects was $2,89 \mathrm{M}$. The distance between the objects corresponded to a visual angle of $1^{\circ} 5^{\prime}\left(55 \mathrm{~mm}\right.$.) and also $2^{\circ} 22^{\prime} 40^{\prime \prime}(12 \mathrm{~cm}$.). The frequéncy of stimulation is expressed in the number of stimuli per $30 \mathrm{sec}$. falling on each retina. The experiments were also carried out with a red and a green object.

In Table I the -results of the experiments are given. Each line in the table contains the mean values of a series of experiments carried out in one session. ${ }^{3}$ The apparatus was only used in preliminary investigations. In further experiments the objects were projected on to a screen by means of a projection-tachystoscope. In this method the wooden boxes with a $3 \mathrm{~mm}$. diameter hole were substituted by luminous spots of $3 \mathrm{~mm}$. diameter projected on to a screen. In all other respects the test set-up was the same as in the preliminary experiments. All figures of Table I were obtained by experiments with the projection-tachystoscope. Our subject had a slight exophoria (Maddox right eye : $36^{\prime}$; left eye : $24^{\prime}$ ).

BITEMPORAL STIMULATION

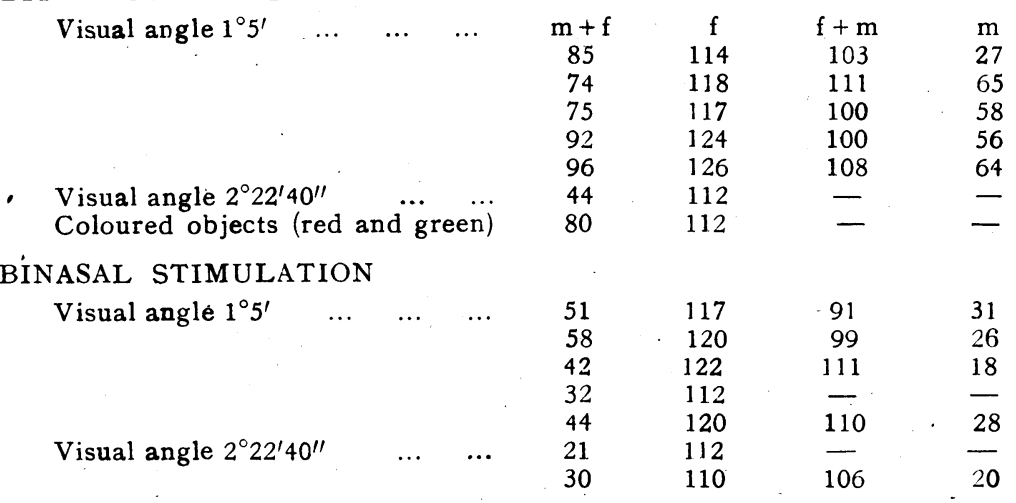

TABLE I

From this table we may conclude :

1. Alternate stimulation with a frequency of $10-20$ stimuli per $30 \mathrm{sec}$. on each retina brings about maximal apparent movement.

2. A shortening of the amplitude of this apparent movement occurred on ' bitemporal stimulation with 74-96 stimuli per 30 sec. on each retina with objects subtending $1^{\circ} 5^{\prime}$; for a visual angle of $2^{\circ} 22^{\prime} 40^{\prime \prime}$ a shortening occurred with 44 stimuli. On binasal stimulation these values were $32-58$ stimuli $/ 30 \mathrm{sec}$. for a visual angle of $1^{\circ} 5^{\prime}$ and $21-30 \mathrm{st}$./30 sec. for a visual angle of $2^{\circ} 22^{\prime} 40^{\prime \prime}$.

These values mark the beginning of fusional movements. 
3. One motionless object was seen when the frequency was $112-126$ for bitemporal stimulation; and 110-122 for binasal stimulation.

These values marked complete fusion of the objects.

4. Lowering of the frequency made the movement appear again. Initial movement occurred with 91-111 stimuli on binasal stimulation and 100-108 stimuli on bitemporal stimulation. With this frequency the motor impulses were no longer strong enough to maintain complete fusion.

5. A further lowering of the frequency results in apparent movement with maximum amplitude. This occurred on bitemporal stimulation with a frequency between 17-65, and on binasal stimulation between 18-31.

6. With coloured objects (one eye was stimulated by a red, the other by a green object), a blending of colours occurred with the same frequency, which caused a fusion of the white objects. This suggested that motor and sensory fusion here occurred with the same frequency.

Fusional movement, however, did not always occur according to this scheme. Fusional movement was impaired especially when the darkness in the room was not complete. In these circumstances increase of frequency resulted in simultaneous perception of both objects, accompanied or not by "jump" apparent movement (see also page 630). In this case the motor impulses elicited by haploscopic alternate stimuli of both retinae followed a different reflex-path. The motor impulses did not bring about a fusional movement (reaction II, see page 630), but led to a localisation of both objects separated in space (reaction III, see page 630). The same phenomenon could be observed if one retina only were stimulated alternately by two objects. With low frequency, maximal apparent movement was seen, with increase in speed of alternation, "jump" apparent movement together with simultaneous perception of both objects separated in space resulted. A further increase gave simultaneous perception of two objects without any apparent movement. In case of stimulation of one retina, reaction III only is elicited.

We then investigated whether the same frequency, which brings about a fusional movement, may also by following another reflex-path give rise to the simultaneous perception of two objects separated in space. For this purpose we drew a comparison between haploscopic alternate stimulation of both retinae and alternate stimulation of one retina only. In case of the former the motor impulses follow the reflex-path of reaction II; with the latter it was reaction III.

We therefore investigated the effect of monocular alternating stimulation in the same way as in the binocular experiments. The right and left eyes were investigated separately and the investigations were performed with and without a fixation-point. The fixation-point made it possible to investigate the effect on the temporal and nasal half of the retinas and also the effect of one stimulus falling on the nasal half and the other on the temporal half of the retina. The objects subtended a visual angle of $\cdot 1^{\circ} 5^{\prime}$. The test set-up was the same as in the binocular experiments, the only difference being that one eye was covered and the screens were removed. The results given in Table II are quoted under five headings:

\section{WITHOUT FIXATION POINT}

$R$. eye

L. eye

$\mathrm{m}$

$\begin{array}{crcc}\mathrm{m}+\mathrm{s} & \mathrm{s} & \mathrm{s}+\mathrm{m} & \mathrm{m} \\ 32 & 108 & 92 & 48 \\ 44 & 92 & 80 & 40\end{array}$

WITH FIXATION-POINT

nasal half of retina:

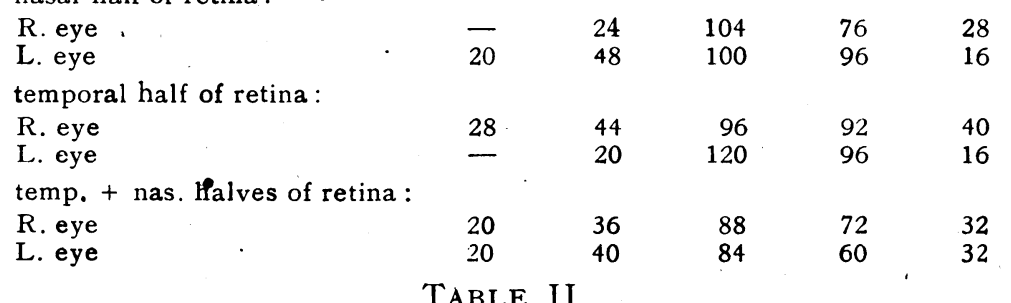

TABLE II 
maximàl apparent movement $(\mathrm{m})$; increase of frequency: apparent movement + simultaneous vision $(m+s)$; simultaneous vision without movement $(\mathrm{s})$; lowering of frequency: simultaneous vision + apparent movement $(s+m)$; maximal apparent movement (m).

These results were compared with the values of the binocular experiments quoted in Table I :

Monocular altern. stim.

$$
\begin{aligned}
\mathrm{m}+\mathrm{s}: & 20-48 \\
\mathrm{~s}: & 84-120 \\
\mathrm{~s}+\mathrm{m}: & 60-96 \\
\mathrm{~m}: & 1648
\end{aligned}
$$

$$
\begin{aligned}
& \text { Binoc. haplosc. altern. stim. } \\
& \text { binasal stım. bitemp. stim. } \\
& \mathrm{m}+\mathrm{f} \text {. 32-51 74-96 } \\
& \text { f : } 110-122 \quad 112-126 \\
& \mathrm{f}+\mathrm{m}: 91-111 \\
& \mathrm{~m}: 18-31 \quad 27-65
\end{aligned}
$$

Considering that it is very difficult for the subject to indicate when he sees two objects without apparent movement (s) and two objects with slight apparent movement $(s+m)$, we may conclude that the values in the two columns fairly agree. These values indicate that the beginning of a fusional movement $(m+f)$ and the beginning of simultaneous perception $(\mathrm{m}+\mathrm{s})$ occurred with about the same frequency of alternation. We may substitute fusion (reaction II) for simultaneous perception (reaction III). In both instances the stimuli are the same; they give rise to identical motor impulses which, however, may follow two reflex-paths-one leading to reaction II (fusion) and the other to reaction III (simultaneous perception). In case of monocular alternate stimuli only reaction III is available, but in binocular haploscopic stimulation reaction II or reaction III may be chosen. It depends on the outer additional circumstances which reflex-pathway is used. When the room was not completely darkened, reaction III (simultaneous perception of two objects) was favoured. In a following article we will prove that this was caused by additional peripheral stimuli from the surroundings. If the influence of these peripheral stimuli was excluded by using a completely darkened room, reaction II (fusion) always occurred.

These experiments concerned fusion and movement in the horizontal direction. We repeated the same experiments with the stimuli placed vertically, one above the other. The experiments for the vertical direction yielded results which were similar to those in the horizontal direction. To obtain fusion in the vertical direction, however, it is necessary to use a smaller distance between the stimulating objects.

\section{Conclusion and Summary}

A theory on the binocular optical reflexes is presented. Each retinal stimulus gives rise to a sensory and a motor impulse. This motor impulse may be responsible for the following reactions :

(I) A sidewards movement of both eyes in the same direction.

(II) A movement of both eyes in opposite directions. These movements may, however, be inhibited, in which case'the motor impulse gives rise to

(III) Localisation of the stimuli separated in space,

(IV) The perception of apparent movement.

An investigation of reactions II, III and IV was carried out by means of alternate haploscopic stimulation of both retinae. By varying the speed of alternation of the stimuli, it was possible 
to analyze the conditions for fusional movements. Haploscopic stimulation with low frequency of alternate stimuli gives rise to reaction IV (maximal apparent movement). Increase of frequency results in a combination of reaction IV with reaction II (apparent movement combined with a fusional movement) or in a combination of reaction IV with reaction III (apparent movement together with simultaneous perception). A further increase of frequency causes reaction IV to disappear and fusion (reaction II) or simul- taneous perception of two objects (reaction III) results. Reactions II and III occur with the same frequency of alternate stimuli and are brought about by motor impulses of the same quality and quantity. These motor impulses may follow different reflex-paths leading to reaction II or reaction III. Additional circumstances may inhibit one reflex-path and favour the other; i.e., alternate haploscopic stimulation of both retinae in a completely darkened room results in reaction II ; if the room is not completely darkened reaction III is favoured.

According to this theory and based on experimental evidence, fusion, localisation and apparent movement are explained as physiological rather than psychological phenomena. They are optical reflexes, of which the physiological correlate is provided by the motor impulses elicited by the retinal stimuli.

\section{LITERATURE}

1. Roelofs. C. O. (1935).-Die optische Localisation. Arch. f. Augenheilk., Bd. 109.

2. VAN DER WaAls, H. G. and Roelfs, C. O. (1930).-Optische Scheinbewegung. Zeitschr. f. Psychol., Bd. 114 and 115.

3. Winkelman, J. E. (1946)-Thesis. Amsterdam.

\section{HYALINE MEMBRANES ON THE POSTERIOR CORNEAL SURFACE}

B Y

P. D. TREVOR-ROPER

LONDON

Hyaline membranes attached to the posterior corneal surface and spanning the anterior chamber are striking curiosities. They may - arise (1) as persistence of embryonic tissues, (2) as detachments of Descemet's membrane and endothelium, or (3) as sheets of inflammatory exudate; the following three cases illustrate each of these groups, and the aetiology is discussed. 